\title{
Extraction of total DNA and optimization of the RAPD reaction system in Dioscorea opposita Thunb.
}

\author{
G.Q. Wen ${ }^{1}$, J. Li ${ }^{1}$, X.H. Liu ${ }^{1}$, Y.S. Zhang ${ }^{1}$ and S.S. Wen ${ }^{2}$ \\ ${ }^{1}$ College of Life Science, China West Normal University, Nanchong, China \\ ${ }^{2}$ Rice and Sorghum Research Institute, Sichuan Academy of Agricultural Sciences, \\ Deyang, China \\ Corresponding author: X.H. Liu \\ E-mail: liuxiaohong0817@aliyun.com
}

Genet. Mol. Res. 13 (1): 1339-1347 (2014)

Received January 14, 2013

Accepted July 20, 2013

Published February 28, 2014

DOI http://dx.doi.org/10.4238/2014.February.28.6

\begin{abstract}
Dioscorea opposita Thunb. has been used as health food and herbal medicinal ingredients in traditional Chinese medicine. In this study, the total DNA of D. opposita Thunb. was extracted using an improved cetyltrimethylammonium bromide (CTAB) method, and the extracted DNA was further used for random amplified polymorphic DNA (RAPD) reaction system by design of the $\mathrm{L}_{16}\left(4^{4}\right)$ orthogonal diagram. The results showed that the improved CTAB method can be used to isolate high-quality and high-concentration DNA, and the optimized protocol can overcome the instability of RAPD reaction system. The knowledge stated here can be used to study the genetic diversity of $D$. opposita Thunb.
\end{abstract}

Key words: Improved cetyltrimethylammonium bromide method; Dioscorea opposita Thunb.; Random amplified polymorphic DNA; Orthogonal design 


\section{INTRODUCTION}

Dioscorea opposita Thunb. (Chinese name shanyao or yam), included in the family Dioscoreaceae, has been an important invigorant in traditional Chinese medicine for many years. It has been applied as an important ingredient for invigorating spleen and stomach, promoting the production of body fluids, benefiting the lung, and invigorating the kidney (Yuan, 2008; Wang et al., 2010; Kim et al., 2011). It is widely distributed in the world and includes at least 600 species. There are many D. opposita Thunb. cultivars that are grown in China (Wei et al., 2008; Hua et al., 2009; Li et al., 2009). Lichuan D. opposita Thunb. is a particular local variety that is mainly distributed in Lichuan City, Hubei Province, China. In 2007, it had been officially listed as a national product of geographical indication and was classified as a key protection species in China (Sun et al., 2010).

According to the literature, the species classification of Dioscoreae mainly relied on their tuber shapes, which had great limitations and resulted in many different species being regarded as the same species, and Lichuan D. opposita Thunb. is no exception (Li et al., 2009). Molecular markers of DNA can be used to reveal the differences, correlation, and genetic relationships among different varieties of species (Hou et al., 2006). For example, Terauchi and Konuma (1994) analyzed a wild yam species with microsatellite polymorphisms, Mignouna et al. (2002) constructed a genetic linkage map of guinea yam and water yam with amplified fragment length polymorphism markers, and Zhou et al. (2005) analyzed the genetic diversity of 28 cultivar varieties of $D$. opposita Thunb. using inter-simple sequence repeat markers. Bousalem et al. (2006) analyzed chromosomal segregation patterns of the American D. opposita Thunb. using 8 simple-sequence repeat markers. Lichuan $D$. opposita Thunb. acts as a featured product in Lichuan City, Hubei Province. However, to date, very little knowledge is known about the variety's origin, phylogeny, diversity, and genetics.

Random amplified polymorphic DNA (RAPD) is an important molecular tool, which was widely applied to study the origin, evolution, relationship analysis, and genetic diversity of species, as well as the construction of genetic linkage maps and gene localization (Gichuki et al., 2003; Liu, 2010; Xing, 2010). Although many reports noted the deficiency known as instability, it can be overcome by strict experimental conditions such as the optimization of the RAPD reaction system. Some experiments demonstrated that the RAPD reaction system is mainly influenced by the concentration of $\mathrm{Mg}^{2+}$, dNTP, Taq DNA polymerase, and primer (Yao et al., 2009; Wang et al., 2011; Yang et al., 2011). Orthogonal design is a commendable and effective tool to analyze multifactor and multilevel experiments; it can be used to explore the interactions between different factors (Ming, 2005). Therefore, a standardized orthogonal table was used to arrange the experiment to optimize the RAPD reaction system in this study. The knowledge stated here is beneficial for studying the genetic diversity of D. opposita Thunb.

\section{MATERIAL AND METHODS}

\section{Solutions and reagents}

Taq DNA polymerase was obtained from Takara Biotech, Dalian, Co. Ltd., China. RAPD primers were synthesized by SBS Genetech, Co. Ltd., China. Extraction buffer I consisted of $100 \mathrm{mM}$ Tris-Cl, pH 8.0, $50 \mathrm{mM}$ ethylenediaminetetraacetic acid (EDTA), and $500 \mathrm{mM} \mathrm{NaCl}, \mathrm{pH} 8.0$. Just prior to use, the solution was adjusted by the addition of $2 \%$ 
$(\mathrm{v} / \mathrm{v}) \beta$-mercaptoethanol ( $\beta$-ME). Extraction buffer II contained 3\% cetyltrimethylammonium bromide (CTAB), $1.4 \mathrm{M} \mathrm{NaCl}, 100 \mathrm{mM}$ Tris-Cl, pH 8.0, and 0.5 M EDTA, pH 8.0. Similarly, $100 \mu \mathrm{L} \mathrm{2 \%}(\mathrm{v} / \mathrm{v}) \beta-\mathrm{ME}$ was added before use. Additional solutions included $2.5 \mathrm{M}$ potassium acetate (KAc), isopropanol, 70\% ethanol, chloroform:isoamyl alcohol (24:1), and sterile water.

\section{Plant materials}

The seeds of Lichuan D. opposita Thunb. were collected in Lichuan City, Hubei Province. Afterward, the seeds were sowed in our experimental field (China West Normal University, Nanchong City, China). Before the experiment, the young leaves of D. opposita Thunb. were collected for DNA extraction.

\section{Modified protocol for genomic DNA extraction}

An improved CTAB method was used to isolate DNA from D. opposita Thunb. and the basal procedures consisted of the following steps.

1) Approximately $1.0 \mathrm{~g}$ leaves and small amounts of polyvinylpyrrolidone powder $(0.1 \mathrm{~g}$ per $1.0 \mathrm{~g}$ leaves) were ground into fine powder in a liquid nitrogen-chilled mortar.

2) The powder was then immediately transferred to a $2-\mathrm{mL}$ centrifuge tube. Subsequently, $1 \mathrm{~mL}$ cold extraction buffer I was added to the tube, and the contents were homogenized quickly by vortexing and allowed to stand at room temperature for about $10 \mathrm{~min}$. Afterwards, the tube was centrifuged at $4^{\circ} \mathrm{C}$ and $8000 \mathrm{rpm}$ for $10 \mathrm{~min}$.

3) The supernatant was discarded, and the precipitate was suspended in $1 \mathrm{~mL}$ preheated extraction buffer II. The mixture was incubated at $65^{\circ} \mathrm{C}$ for at least $1 \mathrm{~h}$ with occasional, gentle shaking. After incubation, the mixture was centrifuged at $4^{\circ} \mathrm{C}$ and $8000 \mathrm{rpm}$ for $10 \mathrm{~min}$.

4) The supernatant was carefully transferred to a new $2-\mathrm{mL}$ centrifuge tube, and then an equal volume of chloroform:isoamyl alcohol (24:1) was added to the tube. The tube was mixed gently by inversion for $1 \mathrm{~min}$, kept at room temperature for $10 \mathrm{~min}$, and centrifuged at $4^{\circ} \mathrm{C}$ and $10,000 \mathrm{rpm}$ for $10 \mathrm{~min}$.

5) The aqueous phase was carefully transferred to a fresh $2-\mathrm{mL}$ centrifuge tube.

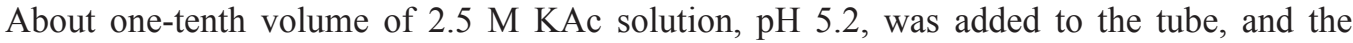
chloroform:isoamyl alcohol (24:1) treatment was repeated as above.

6) The upper aqueous phase was transferred to another new 2-mL tube, and two-thirds volume of ice-cold isopropanol was added to the tube. The tube was maintained at $-20^{\circ} \mathrm{C}$ for more than $30 \mathrm{~min}$ and then centrifuged at $4^{\circ} \mathrm{C}$ and $12,000 \mathrm{rpm}$ for $10 \mathrm{~min}$.

7) The supernatant was discarded, and the pellet containing DNA was washed once or twice with $70 \%$ ethanol and dried under the natural environment.

8) The final DNA precipitate was dissolved in $50 \mu \mathrm{L}$ sterilized double-distilled water.

\section{Determination of the quantity and purity of DNA}

The quality and quantity of the total DNA were determined by monitoring the $\mathrm{A}_{260}$ ' $A_{280}$ absorbance ratio using the NanoDrop 2000. The integrality of the sample was tested by $1.0 \%$ agarose gel electrophoresis with staining by ethidium bromide (EB). Finally, the DNA sample was diluted to a concentration of $50 \mathrm{ng} / \mu \mathrm{L}$. 


\section{Establishment of the RAPD reaction system}

The initial RAPD reaction system was designed as follows: $25 \mu \mathrm{L}$ for one reaction including $2.5 \mu \mathrm{L}$ 10X PCR buffer ( $\mathrm{Mg}^{2+}$-free), $2 \mu \mathrm{L}$ dNTP (2.5 mM each), $2 \mu \mathrm{L} \mathrm{MgCl}_{2}(25$ $\mathrm{mM}), 1 \mu \mathrm{L}$ DNA $(50 \mathrm{ng} / \mu \mathrm{L}), 1 \mu \mathrm{L}$ primer $(20 \mu \mathrm{M}), 0.25 \mu \mathrm{L}$ Taq DNA polymerase $(5 \mathrm{U} / \mu \mathrm{L})$, and $16.25 \mu \mathrm{L} \mathrm{ddH_{2 }} \mathrm{O}$. The RAPD reaction was performed using the following thermal cycle procedures: $94^{\circ} \mathrm{C}$ for $4 \mathrm{~min} ; 40$ cycles of $45 \mathrm{~s}$ at $94^{\circ} \mathrm{C}, 45 \mathrm{~s}$ at $36^{\circ} \mathrm{C}$, and $60 \mathrm{~s}$ at $72^{\circ} \mathrm{C}$; and a final extension step at $72^{\circ} \mathrm{C}$ for $7 \mathrm{~min}$. Amplified PCR products were electrophoresed on a $1.0 \%$ agarose gel with EB in Tris/borate/EDTA (TBE) buffer and photographed on ultraviolet (UV) light. The primers that produced distinct bands were used for the RAPD analysis of the total DNA in D. opposita Thunb.

\section{Optimization of the RAPD reaction system}

Because a large number of studies that revealed RAPD results were influenced significantly by the concentration of $\mathrm{Mg}^{2+}$, dNTP, DNA polymerase, and primer (Yao at al., 2009; Wang et al., 2011; Yang at al., 2011), we optimized the RAPD reaction system using the orthogonal design. In the $20-\mu \mathrm{L}$ reaction system, genomic DNA $(50 \mathrm{ng} / \mu \mathrm{L})$ of D. opposita Thunb. acted as template and SBS A06 (GGTCCCTGAC) acted as primer. To simplify the experiments, the interactions between $\mathrm{Mg}^{2+}$, dNTP, DNA polymerase, and primer concentrations are not taken into account. The experiments of the orthogonal design were designed with 4 factors and 4 levels using the $\mathrm{L}_{16}\left(4^{4}\right)$ array. Orthogonal test factors and level treatment combinations were presented in Tables 1 and 2, respectively. The amplification was performed as above. In this way, the experiment was repeated for the third time. Finally, the optimization of the RAPD reaction system was further confirmed with the SBS B07 (GGTGACGCAG) and the A19 (CAAACGTCGG) primers. Amplified PCR products were electrophoresed on a $1.0 \%$ agarose gel with EB in TBE buffer and photographed on UV light.

Table 1. Factors and levels designed for RAPD system.
\begin{tabular}{lcccc}
\hline Levels & \multicolumn{4}{c}{ Factors } \\
\cline { 2 - 5 } & Primer $(\mu \mathrm{M})$ & $\mathrm{dNTP}(\mathrm{mM})$ & Taq polymerase $(\mathrm{U} / \mu \mathrm{L})$ & $\mathrm{Mg}^{2+}(\mathrm{mM})$ \\
\hline 1 & 0.2 & 0.10 & 0.1 & 1.0 \\
2 & 0.4 & 0.15 & 0.15 & 1.5 \\
3 & 0.6 & 0.2 & 0.2 & 2.0 \\
4 & 0.8 & 0.25 & 0.25 & 2.5 \\
\hline
\end{tabular}

\section{RESULTS}

\section{Purity and integrity of genomic DNA from D. opposita Thunb.}

During the DNA extraction, the physical characteristics of the final DNA pellet were white with no visible discoloration. The quality and purity of the extracted nucleic acid sample was assessed by spectrophotometry with $2 \mu \mathrm{L}$ sample. Using this protocol, the $\mathrm{A}_{260} / \mathrm{A}_{280}$ absorbance ratio of all DNA samples ranged from 2.0 to 2.2 (Table 3), indicating that the nucleic acid that was isolated by this approach was largely free of contaminating proteins. The $\mathrm{A}_{260}$ ' 
$\mathrm{A}_{230}$ ratio was higher than 1.6, indicating that the high-purity DNA samples did not have polyphenol and polysaccharide contamination. In addition, we also found that the DNA quality could be further improved when the DNA samples were precipitated with isopropanol again after washing with $75 \%$ ethanol and being dissolved.

\begin{tabular}{|c|c|c|c|c|}
\hline \multirow[t]{2}{*}{ Test number } & \multicolumn{4}{|c|}{ Factors } \\
\hline & Primer $(\mu \mathrm{L})$ & $\mathrm{dNTP}(\mu \mathrm{L})$ & Taq DNA polymerase $(\mu \mathrm{L})$ & $\mathrm{Mg}^{2+}(\mu \mathrm{L})$ \\
\hline 1 & $1(0.2)$ & $1(0.8)$ & $1(0.4)$ & $1(0.8)$ \\
\hline 2 & 1 & $2(1.2)$ & $2(0.6)$ & $2(1.2)$ \\
\hline 3 & 1 & $3(1.6)$ & $3(0.8)$ & $3(1.6)$ \\
\hline 4 & 1 & $4(2.0)$ & $4(1.0)$ & $4(2.0)$ \\
\hline 5 & $2(0.4)$ & 1 & 3 & 2 \\
\hline 6 & 2 & 2 & 4 & 1 \\
\hline 7 & 2 & 3 & 1 & 4 \\
\hline 8 & 2 & 4 & 2 & 3 \\
\hline 9 & $3(0.6)$ & 1 & 4 & 3 \\
\hline 10 & 3 & 2 & 3 & 4 \\
\hline 11 & 3 & 3 & 2 & 1 \\
\hline 12 & 3 & 4 & 1 & 2 \\
\hline 13 & $4(0.8)$ & 1 & 2 & 4 \\
\hline 14 & 4 & 2 & 1 & 3 \\
\hline 15 & 4 & 3 & 4 & 2 \\
\hline 16 & 4 & 4 & 3 & 1 \\
\hline
\end{tabular}

Table 3. Purity and yield of the genomic DNA extracted from Dioscorea opposita Thunb. by the modified CTAB method.

\begin{tabular}{lrcccc}
\hline Samples & $\mathrm{A}_{260}$ & $\mathrm{~A}_{280}$ & $\mathrm{~A}_{260} / \mathrm{A}_{280}$ & $\mathrm{~A}_{260} / \mathrm{A}_{230}$ & Concentration $(\mathrm{ng} / \mu \mathrm{L})$ \\
\hline 1 & 10.04 & 5.08 & 1.98 & 1.78 & 501.9 \\
2 & 8.74 & 4.11 & 2.13 & 1.59 & 437.2 \\
3 & 7.67 & 3.72 & 2.03 & 1.89 & 383.4 \\
4 & 14.94 & 7.04 & 2.12 & 2.21 & 747.0 \\
\hline
\end{tabular}

To determine the integrity of the DNA, $6 \mu \mathrm{L}$ of each sample was electrophoresed on a 1.0\% agarose gel in TBE buffer. As displayed in Figure 1, the band of the genomic DNA by this protocol is very homogeneous, and no other contamination band appeared, which further confirmed the high purity of the DNA that was extracted by this method and that the DNA was free from polysaccharide and polyphenol contamination. The result of Figure 1 agrees with the results of Table 3 .

We found that the RAPD system had poor repeatability when the selected primers were used again. Consequently, the optimization of the RAPD system for D. opposita Thunb. is very necessary.

\section{Optimization of the RAPD reaction system}

The $\mathrm{L}_{16}\left(4^{4}\right)$ array was used to arrange the tests, and the total test number of a set of the orthogonal design was only 16. The result was analyzed according to Xie's method (Xie et al., 2005). As displayed in Figure 2, there are significant differences among the 16 different combinations of the orthogonal design. Moreover, some combinations did not even result in 
bands, including the first, second, third, eighth, twelfth combinations; additionally, some combinations displayed bad bands such as the tenth and thirteenth combinations. Of these combinations, only the seventh and the ninth combinations displayed good bands, but the band from the ninth combination is more excessive and darker than that from the seventh combination. Therefore, the seventh combination was chosen and used for additional study. That is, the best treatment system consisted of $2.0 \mathrm{mM} \mathrm{Mg}^{2+}, 0.25 \mathrm{U} / \mu \mathrm{L}$ Taq DNA polymerase, $0.1 \mathrm{mM}$ dNTP, and $0.6 \mu \mathrm{M}$ primer.

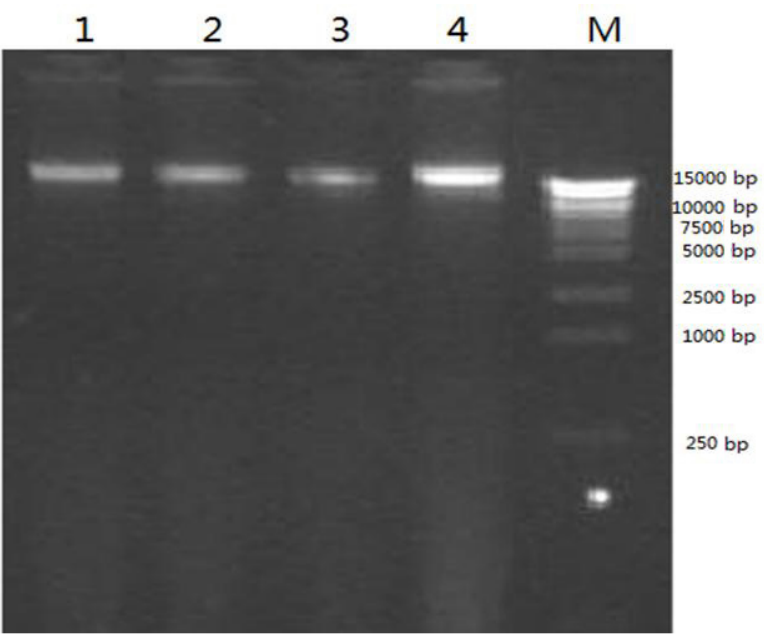

Figure 1. Electrophoresis analysis of the extracted genomic DNA from Dioscorea opposita Thunb. by the modified CTAB method. Lanes 1-4 = DNA samples; lane $M=$ DNA marker.

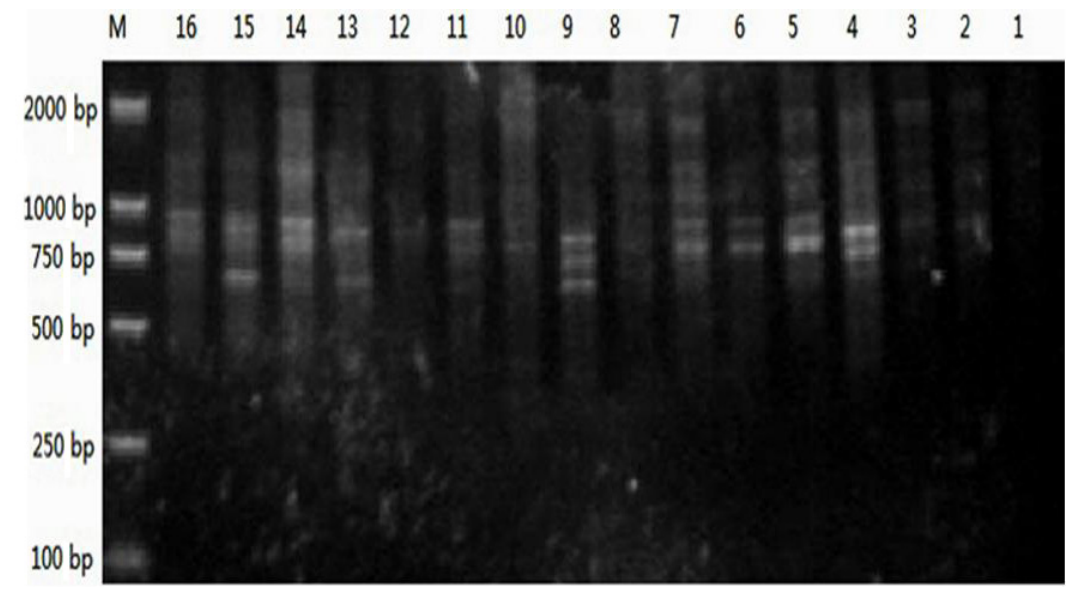

Figure 2. Electrophoresis analysis of the RAPD products based on the orthogonal design diagram. Lane $M=$ DNA marker; lanes 1-16 $=16$ combinations by orthogonal design.

\section{Stability of the optimal reaction system}

The optimized RAPD reaction system was further confirmed using primers SBS B07 
(GGTGACGCAG) and A19 (CAAACGTCGG). The result showed the abundant and legible bands that were displayed in Figure 3, and 3 experimental results were nearly identical. These results showed that the optimized reaction system presented better repeatability, which is suitable for the RAPD analysis of D. opposita Thunb.

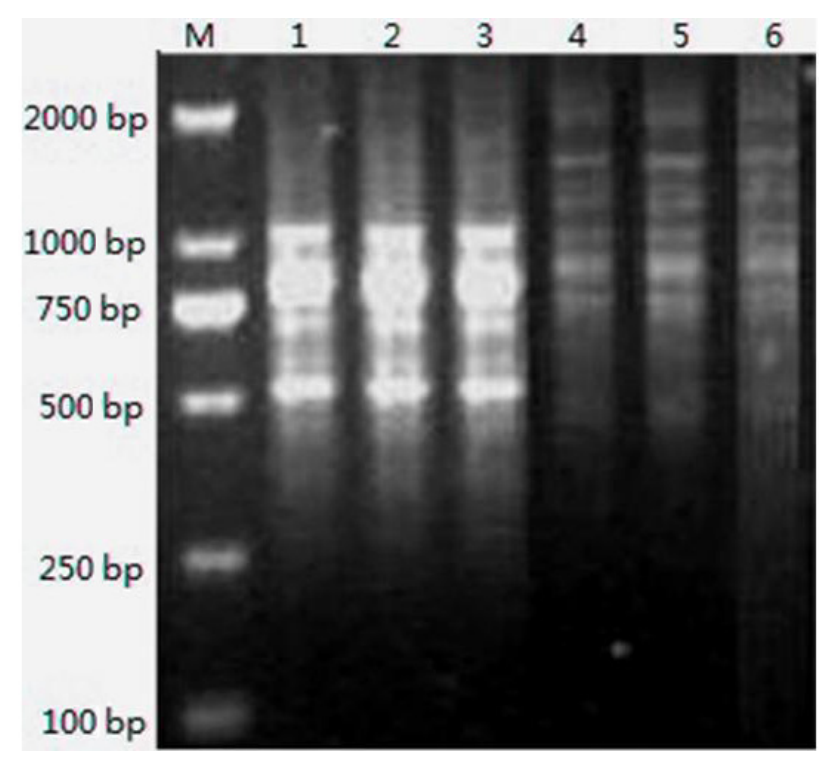

Figure 3. Electrophoresis analysis of RAPD products obtained from the selected best treatment system. Lanes 1-3 = RAPD products using primer SBS B07; lanes 4-6= RAPD products using primer SBS A19; lane $M=$ DNA marker.

\section{DISCUSSION}

It is well-known that high-quality DNA extraction is a critical determinant of molecular biological procedures, such as PCR and gene library construction. However, the extraction methods are probably unsuitable for specific plants because of the physiological and structural differences of the plant itself and the interference of secondary metabolites (Li et al., 2007a; Hu et al., 2009). A great number of studies revealed that D. opposita Thunb. contained abundant mucus that belongs to a complex of mannan-protein and other secondary metabolites (Yuan, 2008; Li et al., 2009). In this study, extraction buffer I was used to partly eliminate polysaccharides. In the extraction and precipitation process, $2.5 \mathrm{M} \mathrm{KAc}$ was used to further remove polysaccharides. The results showed that high-quality DNA was obtained successfully. The isolated DNA was used for many molecular experiments.

The optimization of the RAPD reaction system had been reported for many species (Yao et al., 2009; Wang et al., 2011; Yang et al., 2011). However, previous studies mainly focused on a single factor, which ignored the interactions among multiple factors (Li et al., 2007b). More importantly, the RAPD reaction system is different among the different species and different family members of the same species (Ballard et al., 1996). For instance, Wang et al. (2011) and Yang et al. (2011) optimized the RAPD reaction system of Fritillaria 
unibracteata and Sophora alopecuroides L., respectively. These optimized reaction systems optimized never agreed. Here, the orthogonal design form $\mathrm{L}_{16}\left(4^{4}\right)$ was utilized to arrange the tests to optimize the RAPD reaction system, and the total test number of a set of the orthogonal design was up to 16 . It is obvious that the orthogonal design can significantly reduce the experimental workload and improve the accuracy and efficiency. Finally, a good reaction system for $D$. opposita Thunb. was established. The optimized system is stable and reliable, and it has good repeatability.

In conclusion, the method that we described is an efficient and reliable method to isolate total DNA from $D$. opposita Thunb. At the same time, a suitable RAPD reaction system for $D$. opposita Thunb. was developed. An optimal $20-\mu \mathrm{L}$ reaction system consisted of 2.0 $\mathrm{mM} \mathrm{Mg}{ }^{2+}, 0.25 \mathrm{U} / \mu \mathrm{L}$ Taq DNA polymerase, $0.1 \mathrm{mM} \mathrm{dNTP}$, and $0.6 \mu \mathrm{M}$ primers. The results described here provided some useful information for other related studies on effective DNA extraction and RAPD reaction.

\section{ACKNOWLEDGMENTS}

Research supported by the Scientific Research Fund of Sichuan Provincial Education Department (\#13ZA0012) and the Scientific Research Foundation of China West Normal University (\#07B031) of P.R. China.

\section{REFERENCES}

Ballard R, Rajapakse S, Abbott A and Byrne DH (1996). DNA markers in rose and their use for cultivar identification and genome mapping. Acta Hortic. 424: 265-268.

Bousalem M, Arnau G, Hochu I, Arnolin R, et al. (2006). Microsatellite segregation analysis and cytogenetic evidence for tetrasomic inheritance in the American yam Dioscorea trifida and a new basic chromosome number in the Dioscoreae. Theor. Appl. Genet. 113: 439-451.

Gichuki ST, Berenyi M, Zhang DP and Hermann M (2003). Genetic diversity in sweetpotato [Ipomoea batatas (L.) Lam.] in relationship to geographic sources as assessed with RAPD markers. Genet. Resour. Crop Evol. 50: 429-437.

Hou FY, Zhao B, Wang QM and Li AX (2006). Progress on molecular biology of sweetpotato. Mol. Plant Breed. 4: 119122.

Hu YP, Xie XL, Wang L and Yang J (2009). An effective and low-cost method for DNA extraction from herbal drugs of Rheum tanguticum (Polygonaceae). Afr. J. Biotechnol. 8: 2691-2694.

Hua SM, Tu QC and Lei FG (2009). Genetic diversity of Dioscorea polystachya Turcz revealed by RAPD markers. $J$. Plant Genet. Resour. China 10: 195-200.

Kim SH, Lee SY, Palanivel G and Kwak HS (2011). Effect of Dioscorea opposita Thunb. (yam) supplementation on physicochemical and sensory characteristics of yogurt. J. Dairy Sci. 94: 1705-1712.

Li JT, Yang J, Chen DC, Zhang XL, et al. (2007a). An optimized mini-preparation method to obtain high-quality genomic DNA from mature leaves of sunflower. Genet. Mol. Res. 6: 1064-1071.

Li MJ, Xu X, Zhang XL and Liu YK (2007b). Isolation of genomic DNA and optimization of RAPD conditions of Dioscorea opposita Thunb. J. Henan Normal Univ. 35: 140-143.

Li YX, Huang DY, Huang XL and Wang Y (2009). Progress of study on Dioscorea opposita Thunb. Chin. Agr. Sci. Bull. 25: 91-96.

Liu XY (2010). Overview and application of molecule marker technology of RAPD. Appl. Technol. 9: 98-99.

Mignouna D, Mank A, Ellis N, Van Den Bosch N, et al. (2002). A genetic linkage map of water yam (Dioscorea alata L.) based on AFLP markers and QTL analysis for anthracnose resistance. Theor. Appl. Genet. 105: 726-735.

Ming DX (2005). The Field Experiment and Statistics Analysis. 1st edn. Science Press, Beijing, 247-267.

Sun ZG, Zhong XW, Zhang M and Cheng DL (2010). Protection and development strategies for national products of geographical indication of Rhizoma dioscoreae. Shandong Agr. Sci. 2: 120-123.

Terauchi R and Konuma A (1994). Microsatellite polymorphism in Dioscorea tokoro, a wild yam species. Genome 37: 794-801. 
Wang M, Li DY, Li W and Zheng ZJ (2010). Function of Chinese yam and its utilization. Food Nutr. China 4: 72-75.

Wang W, Hua GH, Gong BQ and Chen Z (2011). RAPD reaction system optimize research in four regions of Fritillaria unibracteata Hsiao et K.C. Hsia. Guangdong Agr. Sci. 38: 149-150.

Wei BH, Gan XQ, Wei WX and Ning XC (2008). Nutritional characteristics and cluster analysis in yam varieties (germplasm) resources. Guangxi Agr. Sci. 39: 596-600.

Xie YH, Xia DA, Jiang J and Lin P (2005). Optimization for ISSR-PCR system of Fraxinus mandshurica Rupr. using orthogonal design. Mol. Plant Breed. 3: 445-450.

Xing XQ (2010). The application of RAPD technique. Food Sci. Technol. 35: 314-316.

Yang YR, Luo HB, Ma Y and Liu P (2011). Optimization of RAPD reaction system in Sophora alopecuroides L. J. Agr. Sci. 32: 26-29.

Yao Y, Chen YS, Li FS and Huang FL (2009). Optimization of RAPD-PCR system and amplification program of dwarf castor. Chin. J. Biol. 22: 284-287.

Yuan SL (2008). Research advances on chemical compositions and bioactivities of Dioscorea opposita Thunb. Food Res. Dev. 29: 176-179.

Zhou YQ, Jing JZ, Li ZY, Hao J, et al. (2005). Genetic diversity of yam (Dioscorea opposita Thunb.) detected by ISSR markers. Shi Yan Sheng Wu Xue Bao 38: 324-330. 